\title{
Effects of Shot Peening on the Torsional Fatigue Limit of High-Strength Steel Containing an Artificial Surface Defect
}

\author{
Koji TAKAHASHI ${ }^{\text {, }}$ Hideki OKADA ${ }^{\text {, }}$ \\ and Kotoji ANDO ${ }^{\text {a }}$
}

${ }^{a}$ Faculty of Engineering, Yokohama National University, 79-5, Tokiwadai, Hodogaya, Yokohama, 240-8501, Japan

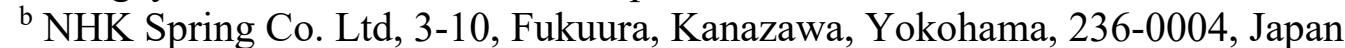

Correspondence:

Dr. Koji Takahashi

Associate Professor

Faculty of Engineering,

Yokohama National University,

79-5, Tokiwadai, Hodogaya, Yokohama, 240-8501, Japan.

E-mail:ktaka@ynu.ac.jp 


\title{
Effects of Shot Peening on the Torsional Fatigue Limit of High-Strength Steel Containing an Artificial Surface Defect
}

\begin{abstract}
Purpose- The purpose of this study is to clarify the effects of shot peening (SP) on the torsional fatigue limit of high-strength steel specimens containing an artificial small defect.

Design/Methodology/Approach- Specimens containing a drilled hole 0.1-0.4 mm deep or a semi-circular slit 0.15 or $0.3 \mathrm{~mm}$ deep were subjected to SP. Torsional fatigue tests were then carried out.

Findings- The torsional fatigue limits of specimens containing a drilled hole and those with a semi-circular slit were increased $25-64 \%$ and $156-186 \%$ by SP, respectively. The torsional fatigue limits of the specimens subjected to SP and containing a drilled hole less than $0.1 \mathrm{~mm}$ in depth or a semi-circular slit less than $0.15 \mathrm{~mm}$ in depth were almost equal to those of SP specimens without a defect. Based on these results, it can be concluded that a drilled hole less than $0.1 \mathrm{~mm}$ in depth and a semi-circular slit less than $0.15 \mathrm{~mm}$ in depth could be rendered harmless by $\mathrm{SP}$.
\end{abstract}

Practical implications - The proposed method can be applied to mechanical parts subjected to cyclic torsion, such as coil springs, crank shafts and drive shafts.

Originality/value- This is the first paper to investigate the torsional fatigue limits after SP in materials containing a surface defect. In this study, we investigated the effect of SP on the torsional fatigue limit having a surface defect.

\section{KEY WORDS}

Torsion, Fatigue limit, Shot peening, High-strength steel, Surface defect, Residual stress.

\section{INTRODUCTION}

The demand for improved fatigue limits of mechanical components is increasing from the perspectives of energy-saving and environmental issues. Introducing compressive residual stresses by shot peening (SP) is a widely used method of improving the fatigue limits of mechanical components (Suresh, 1991; McClung, 2007). Mechanical components, such as coil springs, crank shafts and drive shafts, are subjected to cyclic torsion. Fatigue failure of these components is often caused by surface defects because the maximum stress occurs on the surfaces under cyclic torsion (Das et al., 2007; Fonte et al., 2009). The effects of a small artificial defect on torsional fatigue strength have been studied in various materials using specimens that contain a small artificial hole (Endo and Murakami, 1987; Billaudeau et al., 2004; Tanaka et al., 2006; Susmel and Taylor, 2006), a semi-elliptical surface crack (Murakami and Takahashi, 1998) and a shallow micro-notch (Beretta et al., 2011). In these studies, it is pointed out that the surface defects decreased torsional fatigue limit.

If these defects can be rendered harmless and the fatigue limits of such materials improved through SP, a marked improvement in component reliability and a decrease in costs can be achieved. There have been few studies regarding the effects of SP on materials containing an original surface defect (Renzhi, 1980). More recently, it has been pointed out that the bending fatigue limit of high-strength steel specimens containing a small drilled hole (Takahashi et al., 2007) or a semi-circular slit (Takahashi et al., 2011) can be increased by SP and that small defects, that is, those with a depth of less than 0.1-0.2 mm, can 
be rendered harmless from the viewpoint of the bending fatigue limit. The loading system in these studies was bending rather than torsion; to the best of our knowledge, the effects of SP on the torsional fatigue limit of high-strength steel containing a surface defect have not yet been studied.

In this study, in order to investigate the effects of SP on the torsional fatigue limit of high-strength steel containing an artificial surface defect, we shot peened high-strength steel specimens containing a drilled hole or a semi-circular slit, and then subjected the specimens to a torsional fatigue test.

\section{EXPERIMENTAL PROCEDURES}

\subsection{Test material and specimens}

The material used in this study was JIS SUP9A spring steel. Table 1 shows its chemical composition. Mechanical properties of the material are: $1550 \mathrm{MPa}$ ultimate tensile strength, $1405 \mathrm{MPa} 0.2 \%$ proof stress, and $12 \%$ of elongation. Figure 1(a) shows the shape and dimensions of a torsional fatigue test specimen. In the present study, non-defect specimens, specimens with a drilled hole and specimens with a semi-circular slit were used. Figure 1(b) shows the shape of the drilled hole. The ratio of diameter $(d)$ to depth $(h)$ of the drilled hole was $h=1 / 2 d$. The depths of the drilled hole were $0.1 \mathrm{~mm}, 0.15 \mathrm{~mm}, 0.2 \mathrm{~mm}$ and $0.4 \mathrm{~mm}$. Figure 1(c) shows the shape of the semi-circular slit. The depths of the semi-circular slit were $0.15 \mathrm{~mm}$ and 0.3 $\mathrm{mm}$. The semi-circular slit was introduced parallel to the axial direction by electric discharge machining. The width of the slit $(w=0.03 \mathrm{~mm})$ was very small to simulate an initial crack-like surface defect. It is possible that crack-like surface defects form during the manufacturing process of coil springs (Das et al., 2007). After the specimen was machined, a drilled hole or a semi-circular slit was created at its center. Next, the specimens were oil quenched at $860^{\circ} \mathrm{C}$ and tempered at $420^{\circ} \mathrm{C}$. The Vickers hardness of the specimens after heat treatment was $520 \mathrm{HV}$.

\subsection{SP conditions}

After heat treatment, non-defect specimens and specimens with an artificial surface defect were shot peened. The SP conditions adopted were: $0.62 \mathrm{MPa}$ air pressure, $0.67 \mathrm{~mm}$ shot diameter, $600 \mathrm{HV}$ shot Vickers hardness, $40 \mathrm{~s}$ shot time, $300 \%$ coverage at the specimen surface, and $0.496 \mathrm{mmA}$ arc height.

\subsection{Distribution of residual stress}

Residual stress measurement was carried out using the X-ray diffraction method with a $\mathrm{Cr}-\mathrm{K} \alpha$ beam X-ray spectrum and a 2.0-mm X-ray beam injection diameter. It was difficult to measure the residual stress near the artificial surface defect in this experiment due to the limitations of the beam injection diameter. Therefore, we measured the residual stress distributions outside the artificial surface defect. The residual stress distributions in the thickness direction were obtained by alternately measuring the residual stress on the surface and then chemically etching to remove the surface layer. The residual stresses distributions in \pm $45^{\circ}$ to the axial directions, i.e. the principal stress directions, were measured.

The residual stress distributions are shown in Fig. 2. The surface compressive residual stress was approximately $600 \mathrm{MPa}$. The distance from the surface to the zero residual stress point (crossing point) was about $0.29 \mathrm{~mm}$. 
It is well known that the surface roughness and strain hardening after SP affects fatigue strength of metal. Thus, we measured surface roughness and Vickers hardness before and after SP. Table 2 shows surface roughness before and after SP. The values of surface roughness increased after SP, however, they were much smaller than the depth of either the artificial drilled hole $(0.1-0.4 \mathrm{~mm})$ or the semi-circular slit $(0.15$ and $0.3 \mathrm{~mm})$. Thus, it is considered that the effects of surface roughness on fatigue strength are small. Regarding the Vickers hardness, our measurements found no change in hardness after SP, nor did the hardness change remarkably from the surface to the center of the specimen, as shown in Fig. 3.

\subsection{Fatigue tests}

Torsional fatigue tests were carried out on the specimens using a torsional fatigue testing machine. The fatigue test conditions were a stress ratio of $R=0$ and a cyclic frequency of $20 \mathrm{~Hz}$. The fatigue limit was defined as the maximum torsional stress amplitude under which the specimen endured $10^{7}$ cycles. The fracture appearances and fracture surfaces of all tested specimens were observed using an optical microscope or a scanning electron microscope (SEM).

\section{EXPERIMENTAL RESULTS AND DISCUSSION}

\subsection{Fatigue test results}

Figures 4(a) and (b) show typical examples of the relationship between stress amplitude $\left(\tau_{a}\right)$ and the number of cycles to failure $\left(N_{f}\right)$ for specimens with a drilled hole and specimens with a semi-circular slit. The open circles indicate a non-shot-peened specimen (non-SP); the solid squares indicate shot-peened specimens (SP). The arrow indicates that no fracture had occurred when the test was terminated at $10^{7}$ cycles. The values of the torsional fatigue limit are given. The torsional fatigue limit and fatigue life were increased by SP.

\subsection{Effects of SP on the torsional fatigue limit of specimens with an artificial defect}

Figures 5 and 6 show the results of the torsional fatigue tests for specimens with a drilled hole and with a semi-circular slit, respectively. The solid symbols represent the specimens that failed during torsional fatigue tests; the open symbols represent the specimens that did not fail up to $10^{7}$ cycles, where the maximum stress amplitude corresponds to the torsional fatigue limit. The asterisks indicate that the specimen failed somewhere other than at the drilled hole or semi-circular slit. The dashed lines represent the torsional fatigue limit. The torsional fatigue limit of the non-SP specimens decreased with increasing depth of hole or slit. The decreasing rates of the torsional fatigue limit of specimens with a semi-circular slit (56-66\%) were higher than those of the specimens with a drilled hole (21-36\%). It was found that the torsional fatigue limits of specimens containing a drilled hole or a semi-circular slit were increased $25-64 \%$ or $156-186 \%$, respectively, by SP. Compressive residual stresses are the main reason for these increases in the torsional fatigue limit.

\subsection{Fracture origin}

The fracture appearances and fracture origins of all tested specimens were observed using an optical microscope and an SEM. Figures 7 to 12 show the tested specimens. 
Figure 7 shows a $0.15-\mathrm{mm}$-hole specimen. Specimens of this type failed due to a fatigue crack that initiated from the drilled hole and propagated perpendicular to the principal stress, i.e. $45^{\circ}$ to the axial direction. The 0.1-mm-hole, 0.2-mm-hole and 0.4-mm-hole specimens also failed in the same way. Figure 8 shows a $0.1-\mathrm{mm}$-hole SP specimen. The 0.1-mm-hole SP specimens failed outside the drilled hole. Figure 9 shows a 0.15 -mm-hole SP specimen. The $0.15-\mathrm{mm}$-hole SP specimens failed from the drilled hole, as did the 0.2-mm-hole SP and 0.4-mm-hole SP specimens.

Figure 10 shows a $0.3-\mathrm{mm}$-slit specimen. The $0.3-\mathrm{mm}$-slit specimens failed due to a fatigue crack that initiated from the semi-circular slit and propagated perpendicular to the principal stress, i.e. $45^{\circ}$ to the axial direction. The $0.15-\mathrm{mm}$-slit specimens also failed in the same way. Figure 11 shows a $0.15-\mathrm{mm}$-slit SP specimen. The $0.15 \mathrm{~mm}$-slit SP specimens failed outside the semi-circular slit. Figure 12 shows a $0.3-\mathrm{mm}$ slit SP specimen. The 0.3-mm-slit SP specimens failed from the semi-circular slit. The surface defects were deformed by shot (see Figs. 9 and 12). The main reason why the surface defects are rendered harmless is compressive residual stress induced by SP. Deforming the surface defects also contributes to increasing the fatigue limit.

\subsection{Defect size that can be rendered harmless by SP}

The torsional fatigue limit of the SP specimens with a 0.1-mm-hole was equivalent to that of nondefect SP specimens (see Fig. 5). Moreover, the SP specimens with a 0.1-mm-hole failed outside the drilled hole (see Fig. 8). However, the SP specimens with a $0.15-\mathrm{mm}$-hole failed from the drilled hole (see Fig. 9). Therefore, the size of a drilled hole that can be rendered harmless by SP was determined to be 0.1 $\mathrm{mm}$.

The torsional fatigue limit of the SP specimens with a 0.15 -mm-slit was equivalent to that of nondefect SP specimens (see Fig. 6). Moreover, the SP specimens with a $0.15-\mathrm{mm}$-slit failed outside the semicircular slit (see Fig. 11). However, the $\mathrm{P}$ specimens with a $0.3-\mathrm{mm}$-slit failed from the semi-circular slit (see Fig. 12). Therefore, the size of a surface slit that can be rendered harmless by SP was determined to be $0.15 \mathrm{~mm}$.

In this study it was found that a drilled hole $(h=0.1 \mathrm{~mm})$ and a semi-circular slit $(a=0.15 \mathrm{~mm})$ were rendered harmless by SP. These surface defects reduced the torsional fatigue strength $21 \%$ and $56 \%$, respectively. Thus, SP is a useful technique for increasing the structural integrity of components subjected to cyclic torsion, even if the components have a detrimental surface defect.

\section{CONCLUSIONS}

(1) The torsional fatigue limits of specimens with a drilled hole or a semi-circular slit were increased by SP $25-64 \%$ or $156-186 \%$, respectively. Compressive residual stresses are the main reason for this increase in the torsional fatigue limit.

(2) The torsional fatigue limit of the SP specimens with a $0.1-\mathrm{mm}$-hole was equivalent to that of nondefect SP specimens. The SP specimens with a 0.1-mm-hole failed outside the drilled hole. However, the SP specimens with a $0.15-\mathrm{mm}$-hole failed from the drilled hole. Thus, a drilled hole less than $0.1 \mathrm{~mm}$ in depth was rendered harmless by SP.

(3) The torsional fatigue limit of the SP specimens with a $0.15-\mathrm{mm}$-slit was equivalent to that of nondefect SP specimens. SP specimens with a $0.15-\mathrm{mm}$-slit failed outside the slit. However, the SP specimens 
with a $0.3-\mathrm{mm}$-slit failed from the slit. Thus, a semi-circular slit less than $0.15 \mathrm{~mm}$ in depth was rendered harmless by SP.

(4) SP is a useful technique for increasing the structural integrity of components subjected to cyclic torsion, even if these components have a detrimental surface defect.

\section{ACKNOWLEDGMENTS}

A part of this research has been conducted in the research committee of the acceptable defect size for spring of the Japan Society of Spring Engineers (JSSE). The authors greatly acknowledge members of the committee and staffs of JSSE.

\section{REFERENCES}

Beretta, S., Foletti, S. and Valiullin, K. (2011), "Fatigue strength for small shallow defects/cracks in torsion”, International Journal of Fatigue, Vol.33, pp.287-299.

Billaudeau, T., Nadot, Y. and Bezine, G. (2004), "Multiaxial fatigue limit for defective materials: mechanisms and experiments", Acta Materialia, Vol.52, pp.3911-3920.

Das, S.K., Mukhopadhyay, N.K., Ravi Kumar, B. and Bhattachary, D.K. (2007), "Failure analysis of a passenger car coil spring”, Engineering Failure Analysis, Vol.14, pp.158-163.

Endo, M. and Murakami, Y. (1987), "Effects of an artificial small defect on torsional fatigue strength of Steels", Journal of Engineering Materials and Technology ASME, Vol. 109, Issue 2, pp. 124-129.

Fonte, M. and de Freitas, M. (2009), "Marine main engine crankshaft failure analysis: A case study", Engineering Failure Analysis, Vol.16, pp.1940-1947.

McClung, R. C. (2007), “A literature survey on the stability and significance of residual stresses during fatigue", Fatigue \& Fracture of Engineering Materials \& Structures, Vol. 30, pp. 173-205.

Murakami, Y. and Takahashi, K. (1998), "Torsional fatigue of a medium carbon steel containing an initial small surface crack introduced by tension-compression fatigue: crack branching, non-propagation and fatigue limit”, Fatigue \& Fracture of Engineering Materials \& Structures, Vol. 21, No. 12, pp. 1473-1484.

Renzhi, W. (1980), "Effect of residual stresses of shot peening on the fatigue behaviour of a high strength steel”, Fatigue \& Fracture of Engineering Materials \& Structures, Vol. 2, pp. 413-418.

Suresh, S. (1991), Fatigue of Materials, Cambridge University Press, Cambridge, pp.134-135.

Susmel, L. and Taylor D. (2006), "A simplified approach to apply the theory of critical distances to notched components under torsional fatigue loading", International Journal of Fatigue, Vol.28, pp. 417430.

Takahashi, K., Amano, T., Miyamoto, T., Ando, K., Takahashi, F., Tange, A., Okada H. and Ono, Y. (2007), "Improvement of fatigue strength by shot peening for spring steel specimens containing an artificial surface defect", Transactions of Japan Society of Spring Engineers, No. 52, pp. 9-13.

Takahashi, K., Amano, T., Ando, K. and Takahashi, F. (2011), "Improvement of fatigue limit by shot peening for high-strength steel containing a crack-like surface defect", International Journal of Structural Integrity, Vol. 2, Issue 3, pp. 281-292. 
Tanaka, K., Takahashi, H. and Akiniwa, Y. (2006), "Fatigue crack propagation from a hole in tubular specimens under axial and torsional loading”, International Journal of Fatigue, Vol.28, pp.324334. 


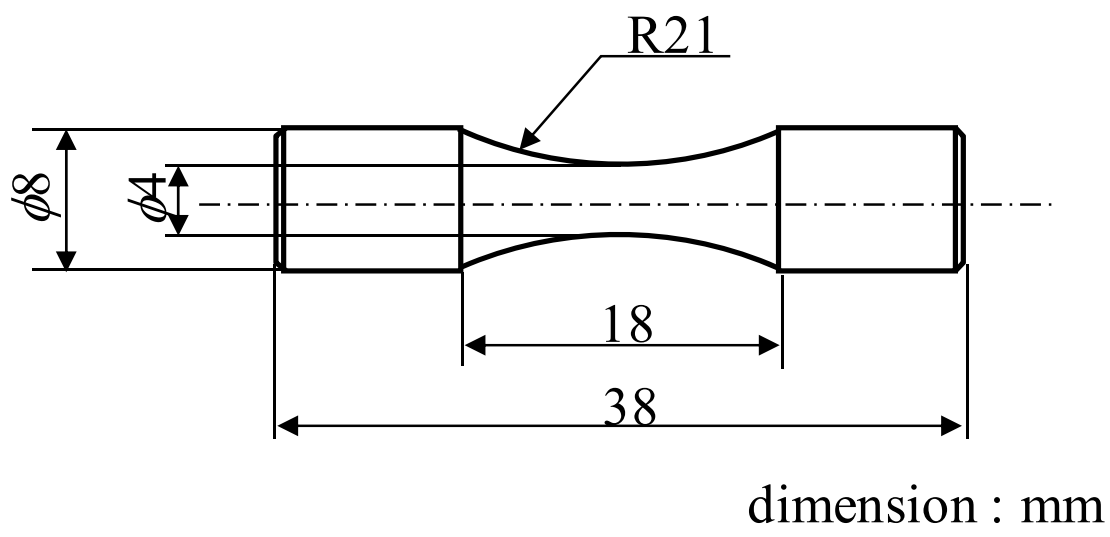

(a) Torsional fatigue test specimen

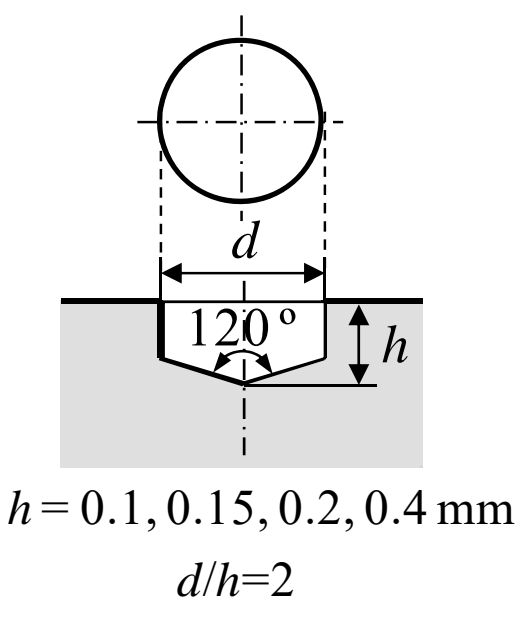

(b) Drilled hole

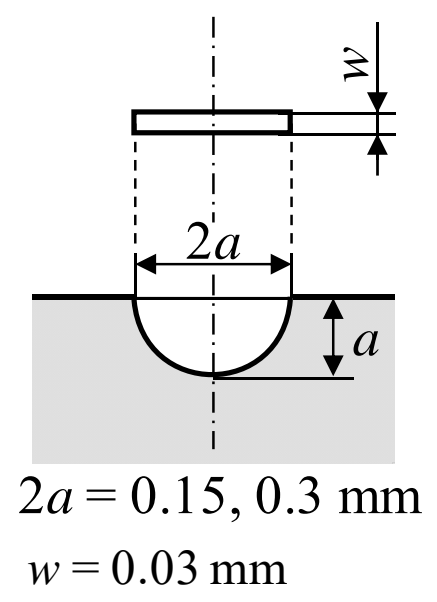

(c) Semi-circular slit

Figure 1. Shape and dimensions of torsional fatigue test specimens and artificial surface defects 


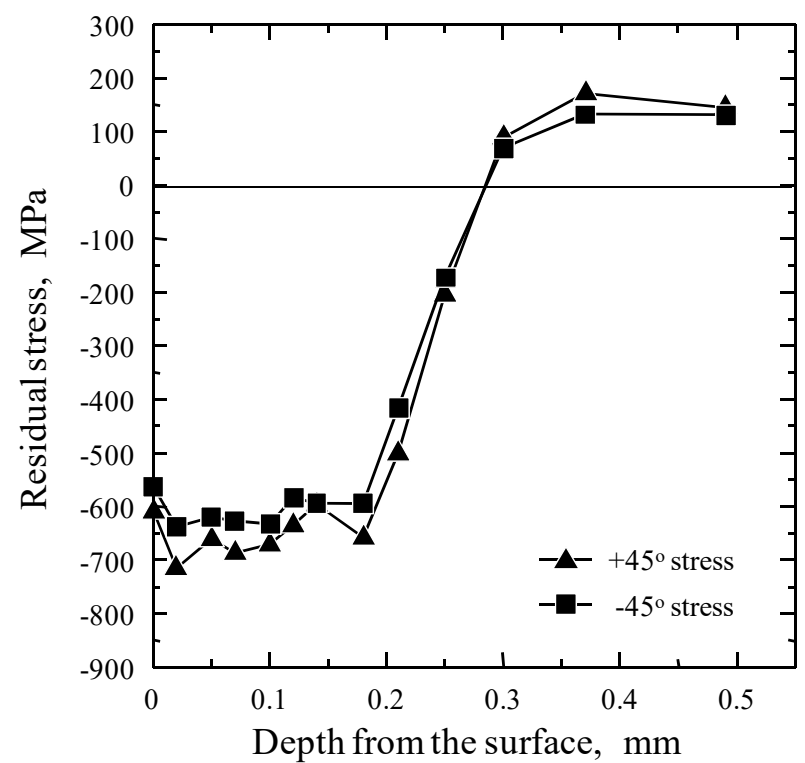

Figure 2. Distribution of residual stress in torsional fatigue test specimens

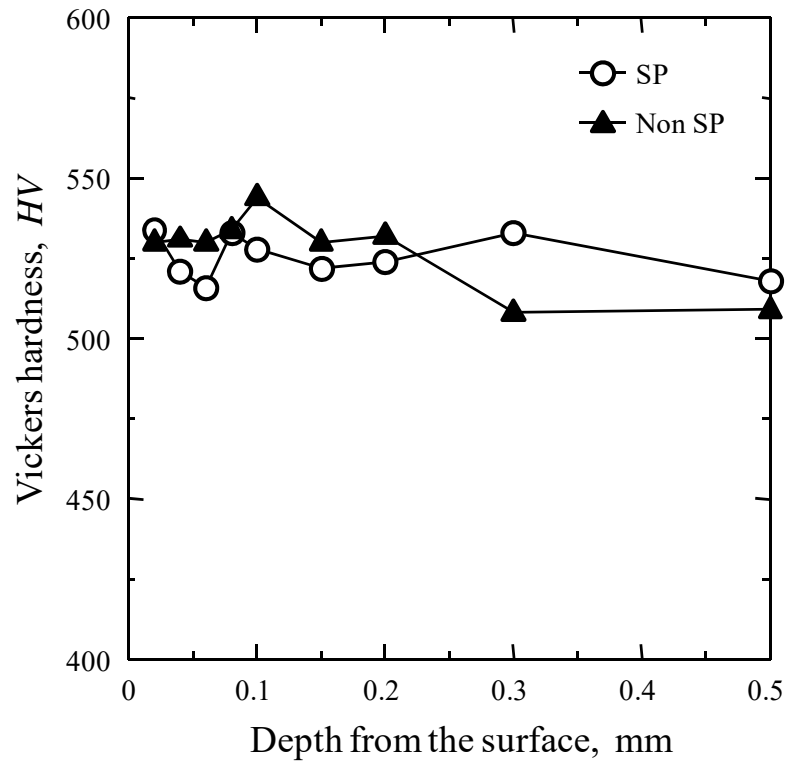

Figure 3. Distribution of Vickers hardness in torsional fatigue test specimens 


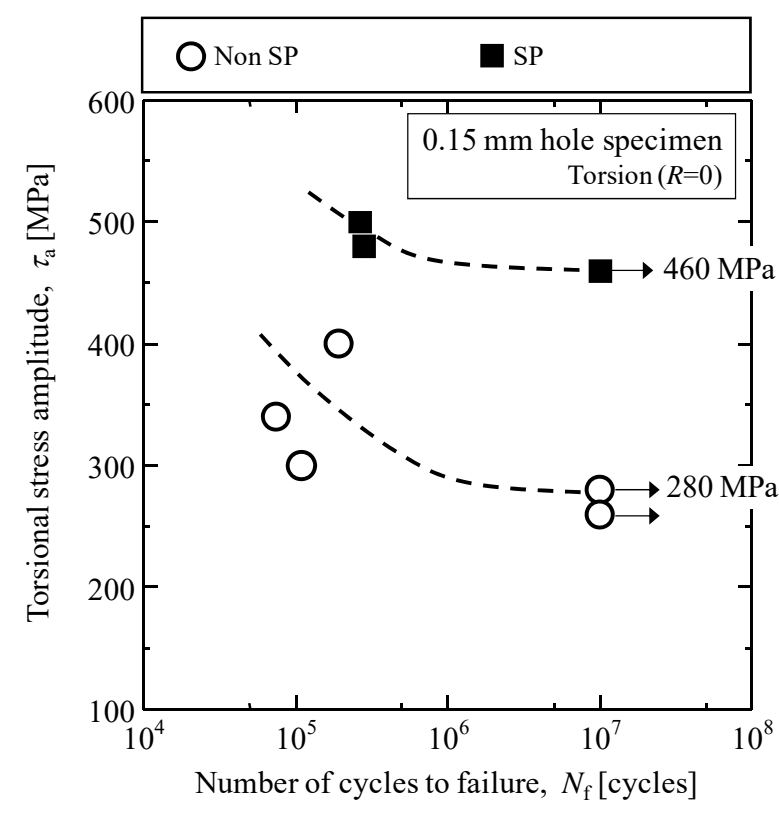

(a) $h=0.15 \mathrm{~mm}$ hole

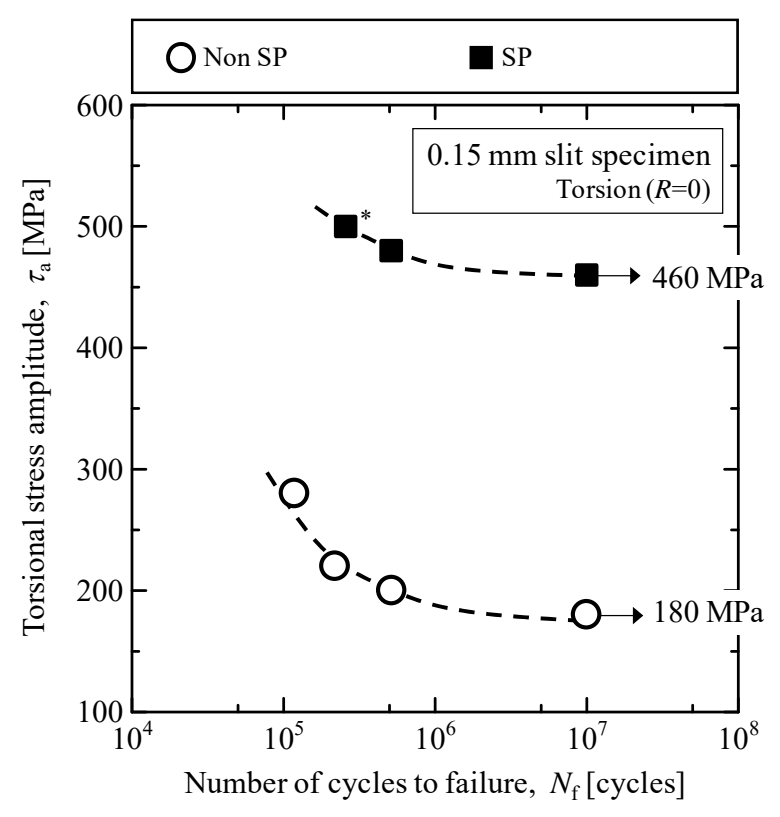

(b) $a=0.15 \mathrm{~mm} \mathrm{slit}$

Figure 4. S-N curves for the torsional fatigue test (SUP9A, $520 \mathrm{HV}, R=0$ )

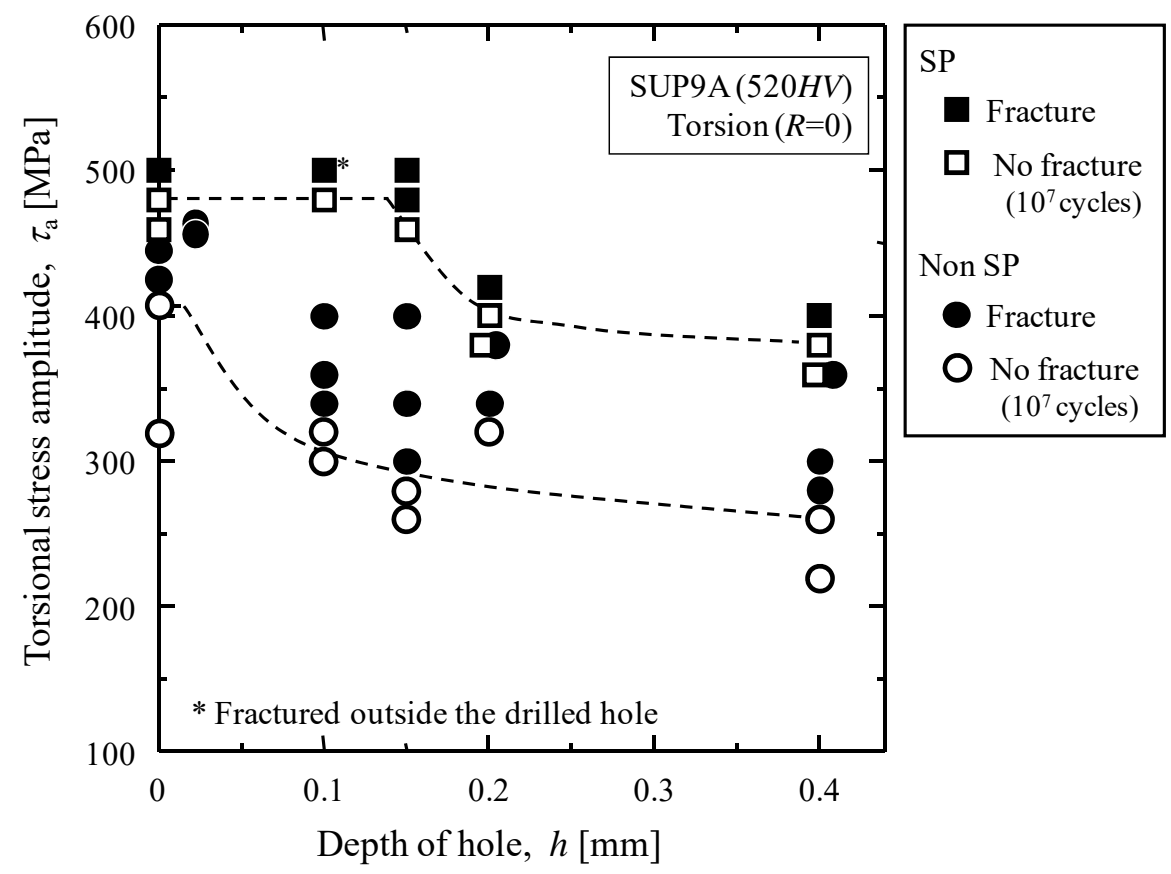

Figure 5. Relationship between stress amplitude and depth of hole (SUP9A, 520HV, torsion, $R=0$ ). 


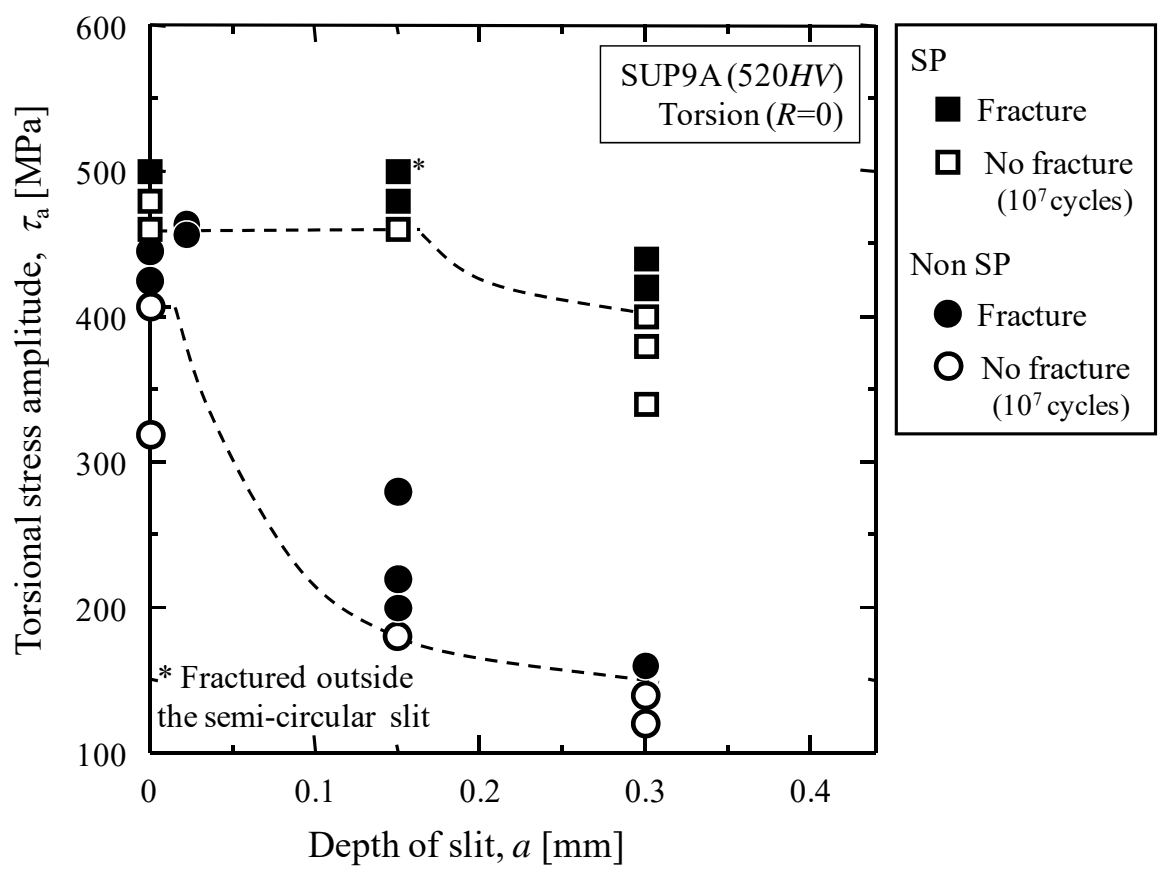

Figure 6. Relationship between stress amplitude and depth of semi-circular slit. (SUP9A, $520 H V$, torsion, $R=0$ )

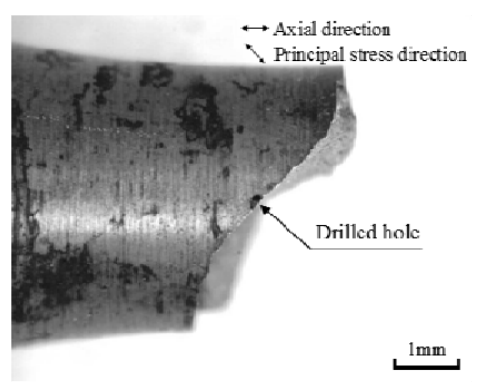

(a) Specimen surface

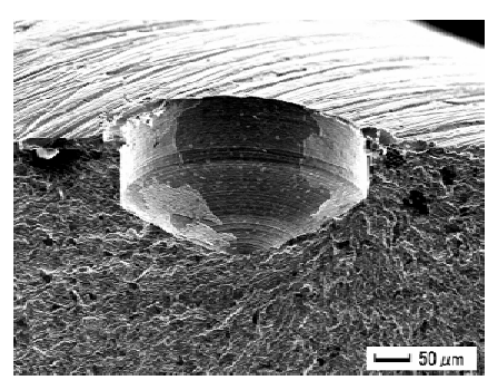

(b) Fracture surface

Figure 7. Photographs of 0.15 -mm-hole specimen after the torsional fatigue test $\left(\tau_{\mathrm{a}}=300 \mathrm{MPa}, N_{\mathrm{f}}=109500\right.$ cycles $)$

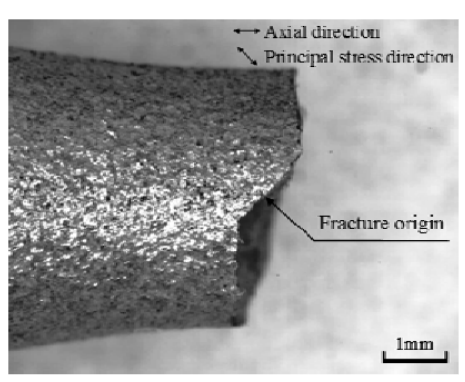

(a) Specimen surface

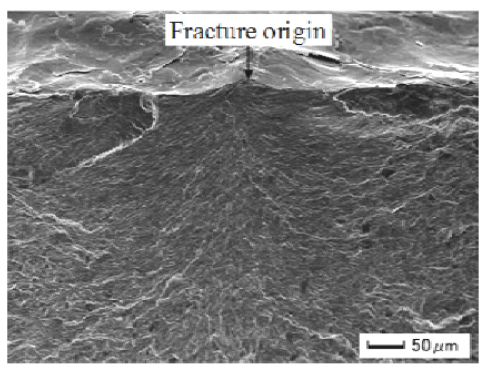

(b) Fracture surface

Figure 8. Photographs of 0.1-mm-hole SP specimen after the torsional fatigue test $\left(\tau_{\mathrm{a}}=500 \mathrm{MPa}, N_{\mathrm{f}}=302800\right.$ cycles $)$ 


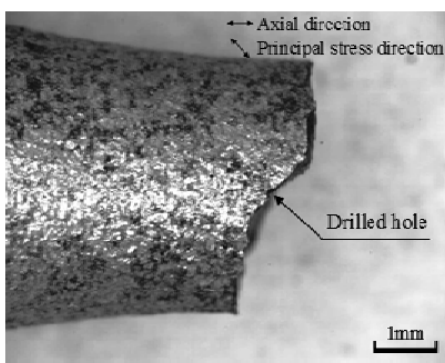

(a) Specimen surface

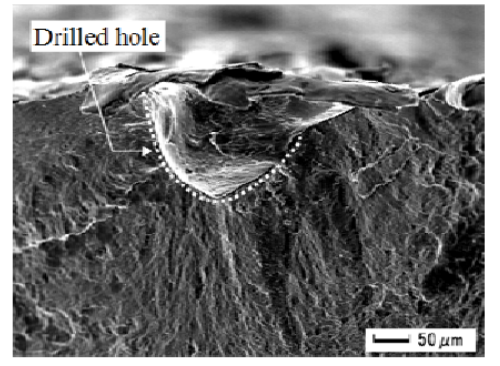

(b) Fracture surface

Figure 9. Photographs of $0.15-\mathrm{mm}$-hole SP specimen after the torsional fatigue test ( $\tau=480 \mathrm{MPa}, N_{\mathrm{f}}=281100$ cycles $)$

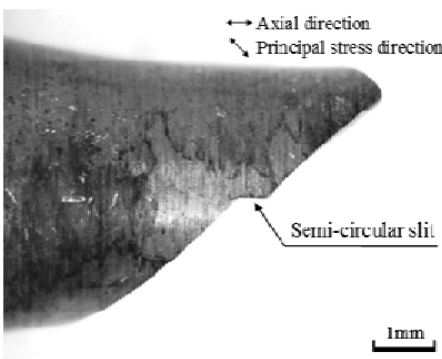

(a) Specimen surface

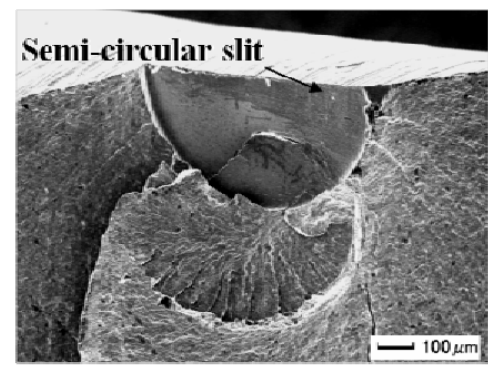

(b) Fracture surface

Figure 10. Photographs of 0.3-mm-slit specimen after the torsional fatigue test $\left(\tau_{\mathrm{a}}=160 \mathrm{MPa}, N_{\mathrm{f}}=417100\right.$ cycles $)$

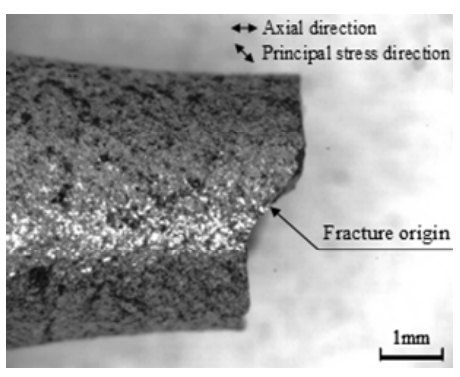

(a) Specimen surface

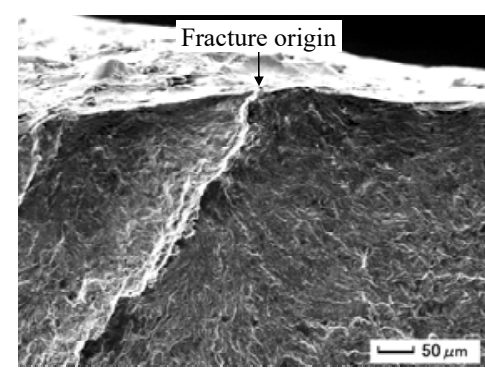

(b) Fracture surface

Figure 11. Photographs of $0.15-\mathrm{mm}$-slit SP specimen after the torsional fatigue test $\left(\tau_{\mathrm{a}}=500 \mathrm{MPa}, N_{\mathrm{f}}=256900\right.$ cycles $)$

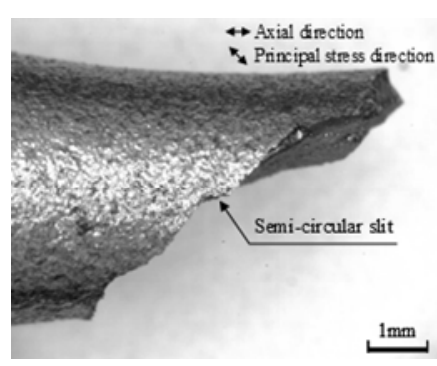

(a) Specimen surface

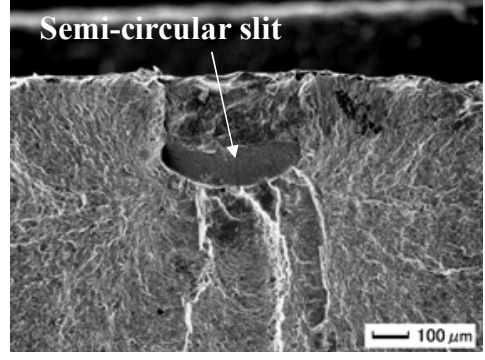

(b) Fracture surface

Figure 12. Photographs of 0.3 -mm-slit SP specimen after torsional fatigue test ( $\tau_{\mathrm{a}}=440 \mathrm{MPa}, N_{\mathrm{f}}=171500$ cycles $)$ 